\title{
Letters
}

\section{Authors' RePly: Prevention of CONGENital Rubella AND CONGENITAL VARICELLA IN EUROPE}

\author{
E Pandolfi (pandolfi.elisabetta@gmail.com) ${ }^{1}$ \\ 1. Epidemiology Unit, Bambino Gesù Paediatric Hospital, Rome, Italy
}

To the editor: We thank the World Health Organization (WHO) Regional Office for Europe for the comments on our article, which add significant details that we may have missed. Obviously, we strongly agree that surveillance represents the basic milestone of prevention strategies, that a lot has to be done, and that surveillance should be enhanced in order to achieve the goal of congenital rubella elimination within the expected time.

Although we may have put more emphasis on the need of high quality surveillance for rubella in the WHO European Region, we tried to underline how prevention strategies should rely on the integration of different activities at different levels. In addition to the enhancement of the existing surveillance systems, surveillance of congenital rubella syndrome (CRS) may benefit from the cooperation with congenital defects registries, which may be explored more deeply.

The role of health providers in informing and recommending appropriate preventive actions is crucial and may be practiced during every medical encounter in the frame of prevention of adverse outcomes of pregnancy. Combining surveillance activities and operative recommendations for clinicians in preconception care will bring the goal of rubella elimination closer and will likely allow achieving other important prevention objectives.

This article was published on 9 April 2009.

Citation style for this article: Pandolfi E. Authors' reply: Prevention of congenital rubella and congenital varicella in Europe. Euro Surveill. 2009;14(14):pij=19168. Available online: http://www.eurosurveillance.org/ViewArticle.aspx?ArticleId=19168 